\title{
Phlebotominae (Diptera: Psychodidae) of human leishmaniosis sites IN TUNISIA
}

\author{
GHRAB J.*, RHIM A.**, BACH-HAMBA D.*, CHAHED M.K.***, AOUN K.*, **, NOUIRA S.**** \\ \& BOURATBINE A.****
}

\section{Summary:}

In order to identify the phlebotomine sandfly populations in Tunisian leishmaniosis foci, an entomological survey was carried out through three entomological seasons (2002-2003-2004) in 19 visceral and cutaneous leishmaniosis areas, located in six bioclimatic zones. Sandfly collections were based on light and sticky traps placed around human leishmaniosis cases. 8,722 phlebotomine sandflies belonging to 12 species were collected. The dominance of subgenus Larroussius species in northern foci, Phlebotomus papatasi in south-western foci and their co-dominance in the centre of the country is in accordance with the distribution of Leishmania infantum and L. major in Tunisia. The low density found in the historical zoonotic cutaneous leishmaniosis focus of Metlaoui in the south-west may indicate the high competence of the local populations. Studied phlebotomine settlements have showed a low specific diversity in most of the studied sites. In L. infantum areas, the dominant species were respectively: $P$. perfiliewi in the cutaneous leishmaniosis site of the humid bioclimatic stage, $P$. perniciosus in the cutaneous and visceral leishmaniosis foci of semi-arid and arid bioclimatic stages and $P$. longicuspis in the visceral leishmaniosis focus of saharan bioclimate. In the zoonotic cutaneous leishmaniosis foci, $P$. papatasi was a dominant species. In the well-known southeastern foci of cutaneous leishmaniosis due to L. killicki, P. sergenti was a dominant species with $P$. perniciosus. In the central emerging foci of L. killicki, P. perniciosus was a dominant species in some sites whereas it was very rare in others. In these sites, the subgenus Paraphlebotomus was always present with a higher abundance of $P$. alexandri than $P$. sergenti.

KEY WORDS : Phlebotominae, visceral leishmaniosis, cutaneous leishmaniosis, Leishmania infantum, Leishmania major, Leishmania killicki, epidemiology, entomology, Tunisia.

\section{INTRODUCTION}

Tr $\mathrm{n}$ Tunisia three species of Leishmania coexist. They occur in particular ecological features and cause human visceral and cutaneous leishmaniosis (Ben

* Unité d'Entomologie, Laboratoire de Parasitologie, Faculté de Médecine de Tunis.

*** Laboratoire de Parasitologie, Institut Pasteur de Tunis.

**:* Département d'Epidémiologie et de Santé Publique, Faculté de Médecine, Tunis.

***** Laboratoire d'Ecologie Animale, Faculté des Sciences, Tunis Correspondance: Dr Aïda Bouratbine, Laboratoire de ParasitologieMycologie, Institut Pasteur de Tunis, 13, place Pasteur, B.P. 74, 1002, Tunis Belvédère, Tunisie.

Tél. : 0021698343479 - E-mail: aida.bouratbine@pasteur.rns.tn
Résumé : Phlebotominae (Diptera : Psychodidae) Des régions De LEISHMANIOSE HUMAINE EN TUNISIE

Afin de caractériser les populations phlebotomiennes des foyers de leishmaniose humaine en Tunisie, une enquête entomologique a été effectuée durant trois saisons entomologiques (2002-2003-2004) dans 19 foyers de leishmanioses viscérale et cutanée, situés dans six sous-étages bioclimatiques. Les collectes de phlébotomes ont été effectuées par des pièges lumineux et adhésifs placés autour des cas humains de leishmaniose. 8722 phlébotomes ont été capturés appartenant à 12 espèces. La dominance des espèces de Larroussius dans les foyers du nord, de P. papatasi dans ceux du sud-ovest et leur codominance au centre du pays est en accord avec la répartition de Leishmania infantum et L. major en Tunisie. La faible densité des phlébotomes trouvée dans le foyer historique de leishmaniose cutanée zoonotique de Métlaoui suggère la haute compétence des populations phlébotomiennes locales. Les peuplements phlébotomiens étudiés ont montré une faible diversité spécifique dans la plupart des sites étudiés. Dans les foyers de L. infantum, les espèces dominantes étaient respectivement P. perfiliewi dans le foyer de leishmaniose cutanée de l'étage bio-climatique humide, P. perniciosus dans les foyers de leishmanioses cutanée et viscérale des étages bioclimatiques semi-aride et aride et P. longicuspis dans le foyer de leishmaniose viscérale de l'étage saharien. Dans les foyers de leishmaniose cutanée zoonotique, P. papatasi était une espèce dominante. Dans les foyers connus de leishmaniose cutanée à L. killicki du sud-est, P. sergenti était l'espèce dominante associée à $P$. perniciosus. Dans les foyers émergents du centre, si P. perniciosus était l'espèce dominante dans certains sites, elle était rarement trouvée dans d'autres. Le sous genre Paraphlebotomus était toujours présent avec une prédominance de $\mathrm{P}$. alexandri par rapport à $\mathrm{P}$. sergenti.

MOTS CLÉS : Phlebotominae, leishmaniose viscérale, leishmaniose cutanée, Leishmania infantum, Leishmania major, Leishmania killicki, épidémiologie, entomologie, Tunisie.

Ismail \& Ben Rachid, 1989). L. infantum occurs in the north and in the centre of the country and causes two forms: visceral leishmaniosis (VLI) and cutaneous leishmaniosis (CLI) (Bouratbine et al., 1998; Aoun et al., 2000). Although Phlebotomus (Larroussius) perniciosus Newstead, 1911 seems to be the main vector, there is no available information concerning the possible role of other species of Larroussius in the transmission of VLI and CLI (Killick-Kendrick, 1990). L. major causes zoonotic cutaneous leishmaniosis (CLM), the most extensive and prevalent form with thousands of cases reported each year since the start of a large epidemic in 1982 (Ben Ismail \& Ben Rachid, 1989; DSSB, 2001). This form is endemic in the centre and the south of 
Tunisia and is transmitted from wild rodents by $P$. (Phlebotomus) papatasi Scopoli, 1786 (Ben Ismail et al., 1987). L. killicki is the agent of a chronic cutaneous leishmaniosis form (CLK). It was known to occur as scarce cases in micro foci located in the south-east (Rioux et al., 1986d). Recently, cases due to L. killicki have been reported in the centre and the south-western Tunisia, in foci of CLM (Bouratbine et al., 2005). The reservoir and the vector of this specie are unknown. The reservoir seems zoonotic, mainly because of the sporadic occurrence of cases and the rural distribution of disease (Ben Rachid \& Ben Ismail, 1989). The vector could belong to the subgenera Paraphlebotomus or Larroussius as described elsewhere for L. tropica, a closely related species to L. killicki (Rioux et al., 1986d; Lawyer et al., 1991; Rioux et al., 1990; Jacobson, 2003; Gebre-Michael et al., 2004).

Since 1980's there has been an increase of case numbers, a geographic range extension and an occurrence of epidemics, which are related to all forms of leishmaniosis recorded in the country. This new epidemiological situation may be connected to changes in land use (urbanisation and especially the mobilisation of water resources) that was carried out in Tunisia in the past few years. These ecological modifications have probably induced an increase in reservoir and vector population densities and changes in their geographical distribution (Ben Ismail \& Ben Rachid, 1989; Rioux \& De la Roque, 2003; Aoun et al., 2004; Baldi et al., 2004). The aim of the present study is to describe the sandflies occurring in different human leishmaniosis sites in Tunisia and to discuss vector role in relation to species distribution and abundance.

\section{MATERIAL AND METHODS}

\section{STUDY AREAS}

- VL sites

The study was carried out in six VL sites, situated in five bioclimatic zones (Fig. 1). Five VL sites are located in different parts of the range of L. infantum. They were from north to south: Ghezala (north, sub-humid), Marthouma (north, lower semiarid) and Ain Jloula (centre, upper arid) which are active sites regularly generating sporadic cases ; Garet Ennam and Sidi Salem (centre, upper arid) which are located near the southern border of the range of L. infantum and where the last cases has been notified respectively in 1988 and 2001 (DSSB, 2001). The $6^{\text {th }}$ site Mahassen (south-west, upper saharan) is the only known focus in the Saharan bioclimatic stage so far. It is an isolated site located outside of the continuous L. infantum range (Anderson, 1934 ; Bouratbine et al., 1998).

\section{- CL sites}

15 CL sites were studied. Regarding the leishmaniosis form they were grouped as follows (Fig. 2):

- three CLI sites: Ain Somra (north, sub-humid) and Jmila (north, lower humid) are active foci of CLI (Aoun et al., 2000). Nchem (north, middle semi-arid) is an emerging epidemic focus located in the southern border of CLI area (Belhadj et al., 2003);

- six CLM active sites located in different parts of the area of L. major (Ben Ismail \& Ben Rachid, 1989): Zemla and Sidi Salem (centre, upper arid); Aouabdia (south-west, upper arid); Mahassen, Ras Dhraa and Boulifa (south-west, upper saharan);

- six CLK sites: two well known sites (Rioux et al., 1986c), Nsefri and Rogba, located in the south-east, in Lower arid bioclimate and four new sites, which are confirmed or probable mixed foci of CLK and CLM (Bouratbine et al., 2005). Ghanzour and Ennajeh (centre, upper arid) are located between the northern CLI area and the septentrional border of CLM area. In these emergent foci, L. killicki was isolated but the presence of L. major and L. infantum is also suspected. Gouleb (Centre, Upper arid) and Metlaoui (South-west, Upper arid) are confirmed mixed foci.

\section{SAMPLE COLLECTIONS}

Captures of phlebotomine sandflies were carried out through three entomological seasons: between July and October 2002 mainly in the north, from May to November 2003 in the south and from June to November 2004 mainly in the centre of the country.

All captures were done in anthroponized biotopes, around confirmed leishmaniosis cases. Target stations were houses with yards (used as resting places) and adjacent animal sheds (sheep, cows, dogs, chickens). Collections were based on CDC light-traps and sticky papers (Rioux et al., 1982) placed indoors, outdoors and in animal sheds. Traps were placed before sunset and taken in the following morning. Some stickytrap were left five nights according to weather conditions and to CDC output. Repeated samples were carried out in the entomological season in all L. major and/or L. killicki sites. L. infantum sites were sampled once.

Collected sandflies were identified according to morphological characters described by Croset et al. (1978) and by Léger et al. (1983) for Larroussius female's.

\section{ANALYSIS}

To characterize phlebotominae settlements of different human leishmaniosis sites the following ecological parameters and indexes were calculated separately for captures using sticky traps and those obtained with CDC traps: 
- Relative abundance $\left(\mathrm{A}_{\mathrm{r}}\right)=$

Number of specimens of taxon $i$

Total number of phlebotomines in the sample $\times$ $\times 100$

- Degree of presence (D)*

$\frac{\text { Number of foci containing the species } \mathrm{i}}{\text { Total number of foci }} \times 100$

$$
\text { Total number of foci }
$$

*D was the only parameter calculated from mixed CDC and sticky traps captures

- Density (d): number of phlebotomines per $\mathrm{m}^{2}$ of sticky paper per night $\left(\mathrm{ph} / \mathrm{m}^{2} /\right.$ night $)$

- Specific richness (S): number of species in the sample (Spellerberg \& Fedor, 2003).

Besides specific richness, specific diversity was also measured by indexes diversity that expresses simulta- neously relation between number of species and number of individuals (Spellerberg \& Fedor, 2003).

- Index of Simpson $\left(\mathrm{I}_{\mathrm{s}}\right)=\frac{1}{\sum \mathrm{p}_{\mathrm{i}}^{2}}$

$\mathrm{p}_{\mathrm{i}}=\operatorname{Ar} / 100$

$\mathrm{I}_{\mathrm{S}}$ vary between 1 and $\mathrm{S}$

$I_{S}=1$ : dominance of one species

$I_{S}=S$ : species having equal abundance

- Equitability $(E)=\frac{I_{S}-1}{S-1}$

E vary between 0 and 1

$\mathrm{E}=0$ : dominance of one species

$I_{S}=1$ : species having equal abundance

Statistical analyses were performed with Epi-info and SPSS Software packages. $\chi^{2}$ test and Kruskal-Wallis test

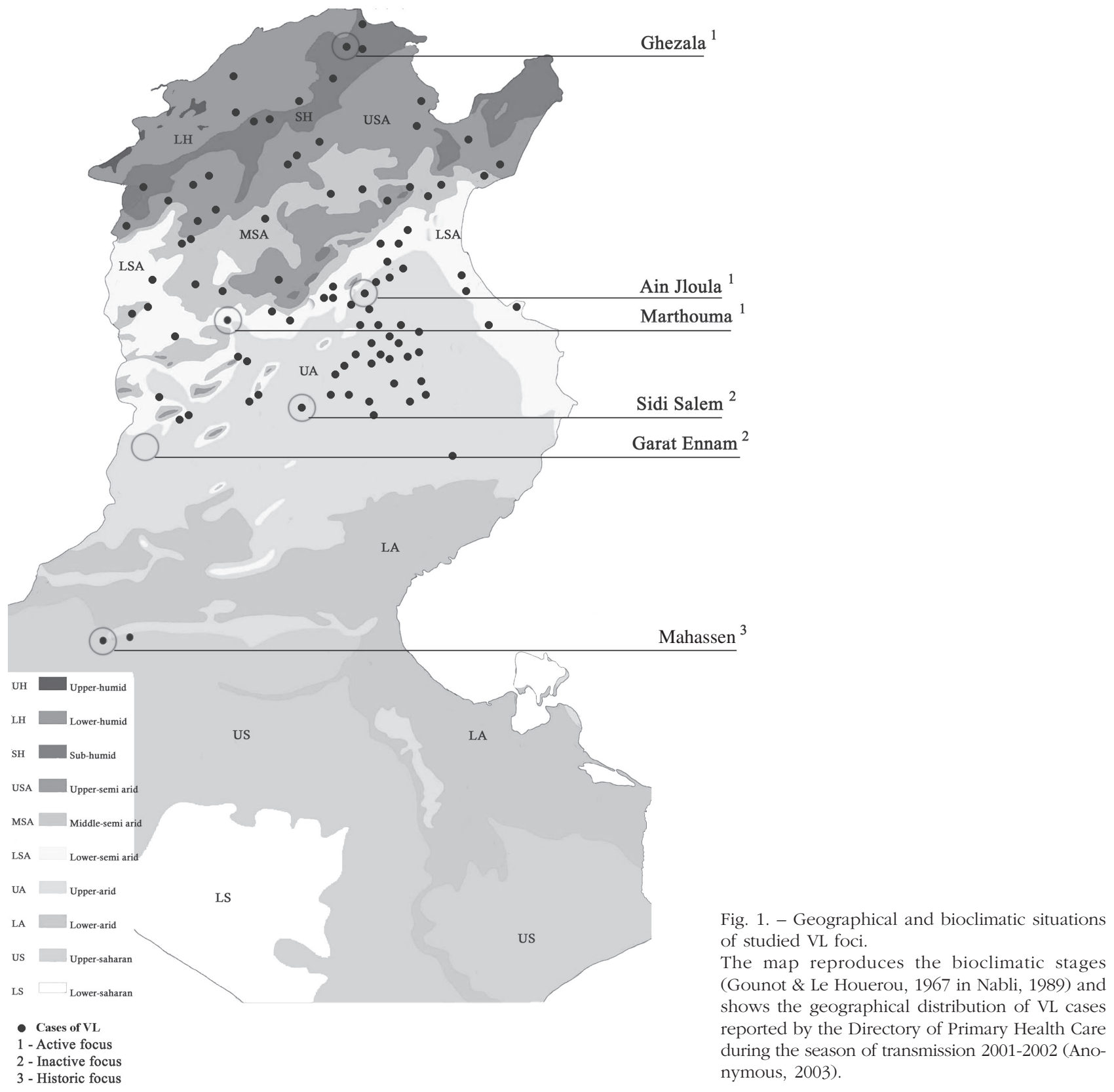


were used to compare percentages and averages respectively.

\section{RESULTS}

\section{GLOBAL RESUlTS}

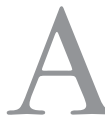
total of 8,722 phlebotomine sandflies were collected and morphologically identified as follows: P. (L.) perniciosus Newstead, 1911: 3,395 (38.9 \%); P. (L.) perfiliewi Parrot, 1939: 2,256 (25.9\%); P. (L.) longicuspis Nitzulescu, 1930: 266 (3 \%); P. (L.) langeroni Nitzulescu, 1930: 46 (0.5 \%); P. (Paraphle- botomus) alexandri Sinton, 1928: 194 (2.2 \%); P. (Pa.) sergenti Parrot, 1917: 126 (1.4 \%); P. (Pa.) chabaudi Croset, Abonnenc et Rioux, 1970: 3 (0.03 \%); P. (Ph.) papatasi (Scopoli, 1786): 991 (11.4 \%) Sergentomyia (Sergentomyia) fallax Parrot, 1921: 816 (9.4\%); S. (S.) minuta parroti Adler et Theodor, 1927: 540 (6.2\%); S. (S.) antennata (Newstead, 1912): 60 (0.7\%) and S. (Grassomyia) dreyfussi Parrot, 1933: 29 (0.3 \%) (Tables Ia and Ib).

The mean density was significantly different according to the regions. It was high in the north (in humid, subhumid and semi-arid bioclimatic stages) (mean density $=$ $29.3 \pm 25.8 \mathrm{ph} / \mathrm{m}^{2} /$ night $)$ still important in arid foci of the centre (mean density $=13.9 \pm 17.7 \mathrm{ph} / \mathrm{m}^{2} /$ night)

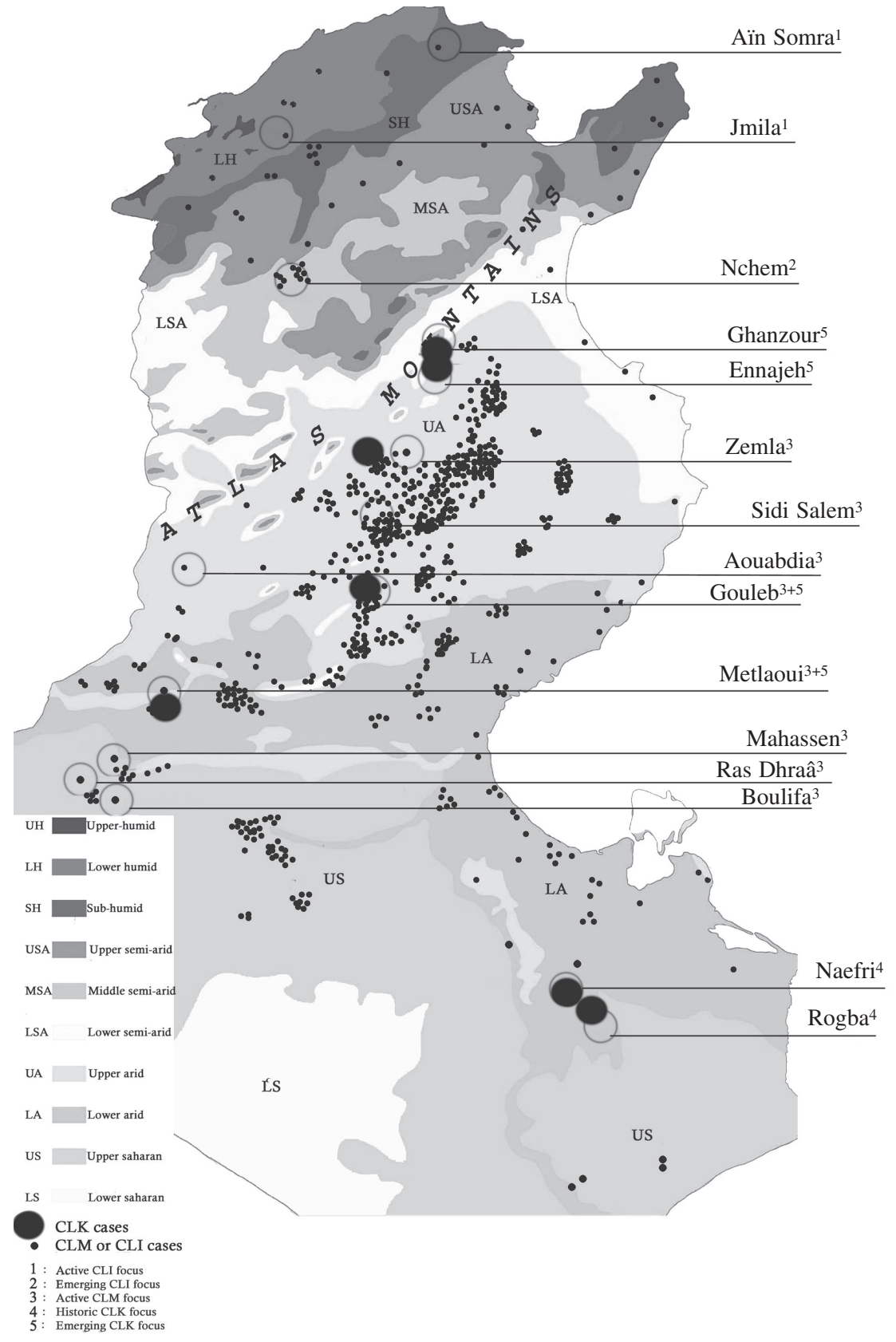

Fig. 2. - Geographical and bioclimatic situations of studied CL foci.

The map reproduces the bioclimatic stages (Gounot \& Le Houerou, 1967 in Nabli, 1989) and shows the geographical distribution of CL cases reported by the Directory of Primary Health Care during the season of transmission 2001-2002 (Anonymous, 2003). 
and decreased in southern foci (mean density $=0.56 \pm$ $1.07 \mathrm{ph} / \mathrm{m}^{2} /$ night $)$ (Fig. 3) ( $<0.01 \%$ ).

$P$. papatasi and S. minuta parroti were common species and showed the largest distribution as indicated by the high degree of presence (D). They were collected from 18 foci out of the 19 prospected ( $\mathrm{D}=94.7 \%$ ).
P. perniciosus was also a common species with a large distribution ( $\mathrm{D}=84 \%)$. P. langeroni was collected only from Nchem ( $\mathrm{D}=5.3 \%)$. It was the first report of this female specie in Tunisia (Ghrab et al., 2005). P. chabaudi also a rare species, was collected from two localities in the southeast ( $\mathrm{D}=10.5 \%$ ) (Tables Ia and $\mathrm{Ib}$ ).

\begin{tabular}{|c|c|c|c|c|c|c|c|c|c|c|c|c|c|c|c|}
\hline \multirow[b]{2}{*}{ Foci } & \multicolumn{2}{|c|}{ CDC traps } & \multicolumn{12}{|c|}{ Species } & \multirow[b]{2}{*}{ Tota } \\
\hline & $\mathrm{nb}$ & nights & perf. & pern. & long. & lang. & se.r & ale. & chab. & Pap. & fal. & min. & ant. & dre. & \\
\hline Jmila & 6 & 1 & 1,986 & 243 & 6 & - & - & - & - & 3 & 2 & 33 & - & - & 2,273 \\
\hline Ghezala & 3 & 1 & 4 & 38 & 1 & - & - & - & - & 13 & - & 103 & - & - & 159 \\
\hline A. Somra & 3 & 1 & - & 7 & 1 & - & - & - & - & 3 & - & 3 & - & - & 14 \\
\hline Nchem & 6 & 1 & 34 & 1,130 & 68 & 41 & - & - & - & 6 & 1 & 10 & - & - & 1,290 \\
\hline Marthouma & 6 & 1 & 11 & 96 & 12 & - & 1 & 1 & - & 1 & 4 & 1 & - & - & 127 \\
\hline Ghanzour & 12 & 3 & 4 & 321 & 58 & - & 9 & 83 & - & 244 & 213 & 30 & 4 & 16 & 982 \\
\hline Ennajeh & 15 & 3 & 3 & 526 & 51 & - & 10 & 37 & - & 112 & 63 & 7 & 4 & 2 & 815 \\
\hline A. Jloula & 1 & 1 & - & 56 & - & - & - & 5 & - & 52 & 29 & - & - & 1 & 143 \\
\hline G. Ennam & - & - & - & - & - & - & - & - & - & - & - & - & - & - & 0 \\
\hline Zemla & - & - & - & - & - & - & - & - & - & - & - & - & - & - & 0 \\
\hline S. Salem & 9 & 3 & 4 & 53 & 13 & - & - & 2 & - & 53 & 5 & 7 & - & - & 137 \\
\hline Gouleb & 9 & 3 & - & 4 & - & - & - & 23 & - & 24 & 232 & 88 & - & 2 & 373 \\
\hline Metlaoui & 38 & 10 & - & - & - & - & - & 3 & - & 9 & 1 & 3 & 1 & & 17 \\
\hline Aouabdia & 19 & 6 & - & - & - & - & - & - & - & 20 & - & - & 2 & 2 & 24 \\
\hline Nsefri & 25 & 10 & - & 58 & - & - & 60 & 6 & 2 & 40 & 21 & 3 & 9 & - & 199 \\
\hline Rogba & 19 & 7 & - & 19 & - & - & 34 & 1 & 1 & 89 & 34 & 2 & 6 & 3 & 189 \\
\hline Mahassen & 19 & 6 & - & 4 & 12 & - & - & - & - & 31 & 1 & - & 2 & - & 50 \\
\hline R Dhraâ & 15 & 6 & - & - & - & - & - & - & - & 7 & 1 & 10 & 5 & 1 & 24 \\
\hline Boulifa & 15 & 5 & - & - & 5 & - & - & - & - & 3 & 1 & 7 & - & - & 16 \\
\hline Total & 220 & 68 & 2,046 & 2,555 & 227 & 41 & 114 & 161 & 3 & 710 & 608 & 307 & 33 & 27 & 6,832 \\
\hline
\end{tabular}

perf: P. perfiliewi; pern.: P. perniciosus; long.: P. longicuspis; lang.: P. langeroni; ser.: P. sergenti; ale.: P. alexandri; chab.: P. chabaudi; pap.: P. papatasi; fal.: S. fallax; min.: S. minuta parroti; ant.: S. antennata; dre.: S. dreyfussi.

Table Ia. - Distribution of phlebotomine species caught by CDC traps in the studied leishmaniosis sites.

\begin{tabular}{|c|c|c|c|c|c|c|c|c|c|c|c|c|c|c|c|}
\hline \multirow[b]{2}{*}{ Foci } & \multicolumn{2}{|c|}{ Stiky traps } & \multicolumn{12}{|c|}{ Species } & \multirow[b]{2}{*}{ Total } \\
\hline & $\mathrm{M}^{2}$ & nights & perf. & pern. & long. & lang. & se.r & ale. & chab. & Pap. & fal. & min. & ant. & dre. & \\
\hline Jmila & 5 & 1 & 44 & 24 & - & - & - & - & - & 2 & - & 11 & - & - & 81 \\
\hline Ghezala & 3 & 5 & 2 & 28 & 1 & - & - & - & - & 38 & - & 96 & - & - & 165 \\
\hline A. Somra & 4 & 5 & 1 & 30 & 2 & - & - & - & - & 3 & - & 63 & - & - & 99 \\
\hline Nchem & 5 & 1 & 5 & 252 & 6 & 5 & - & - & - & - & - & - & - & - & 268 \\
\hline Marthouma & 4 & 1 & 158 & 73 & 2 & - & - & 1 & - & 6 & 3 & - & - & - & 243 \\
\hline Ghanzour & 6,3 & 2 & - & 151 & 6 & - & 5 & 25 & - & 84 & 120 & 6 & 6 & 2 & 405 \\
\hline Ennajeh & 4 & 2 & - & 165 & 6 & - & - & 2 & - & 1 & 5 & - & - & - & 179 \\
\hline A. Jloula & 1.3 & 1 & - & 41 & - & - & 1 & 2 & - & 9 & - & - & - & - & 53 \\
\hline G. Ennam & 19.5 & 20 & - & - & - & - & - & - & - & - & - & 5 & - & - & 5 \\
\hline Zemla & 11.7 & 15 & - & 37 & 4 & - & 1 & - & - & 53 & 3 & 16 & 10 & - & 124 \\
\hline S. Salem & 9 & 15 & - & 33 & 2 & - & - & - & - & 23 & - & 6 & 1 & - & 65 \\
\hline Gouleb & 9.8 & 15 & - & - & - & - & - & 2 & - & 4 & 65 & 19 & - & - & 90 \\
\hline Metlaoui & 19.5 & 10 & - & 1 & - & - & 2 & - & - & 9 & - & 2 & 1 & - & 15 \\
\hline Aouabdia & 20 & 6 & - & - & 2 & - & - & - & - & 22 & 1 & 5 & 4 & - & 34 \\
\hline Nsefri & 17 & 6 & - & 4 & - & - & 3 & 1 & - & 14 & 7 & - & 1 & - & 30 \\
\hline Rogba & 1 & 1 & - & - & - & - & - & - & - & 2 & 1 & - & - & - & 3 \\
\hline Mahassen & 34 & 11 & - & - & 4 & - & - & - & - & 3 & 3 & 2 & - & - & 12 \\
\hline R Dhraâ & 14.1 & 6 & - & - & - & - & - & - & - & 6 & - & 2 & 3 & - & 11 \\
\hline Boulifa & 14.9 & 5 & - & 1 & 4 & - & - & - & - & 2 & - & - & 1 & - & 8 \\
\hline Total & 203 & 128 & 210 & 840 & 39 & 5 & 12 & 33 & 0 & 281 & 208 & 233 & 27 & 2 & 1,890 \\
\hline
\end{tabular}

perf:: P. perfiliewi; pern.: P. perniciosus; long.: P. longicuspis; lang.: P. langeroni; ser.: P. sergenti; ale.: P. alexandri; chab.: P. chabaudi; pap.: P. papatasi; fal.: S. fallax; min.: S. minuta parroti; ant.: S. antennata; dre.: S. dreyfussi.

Table Ib. - Distribution of phlebotomine species caught by sticky traps in the studied leishmaniosis sites. 


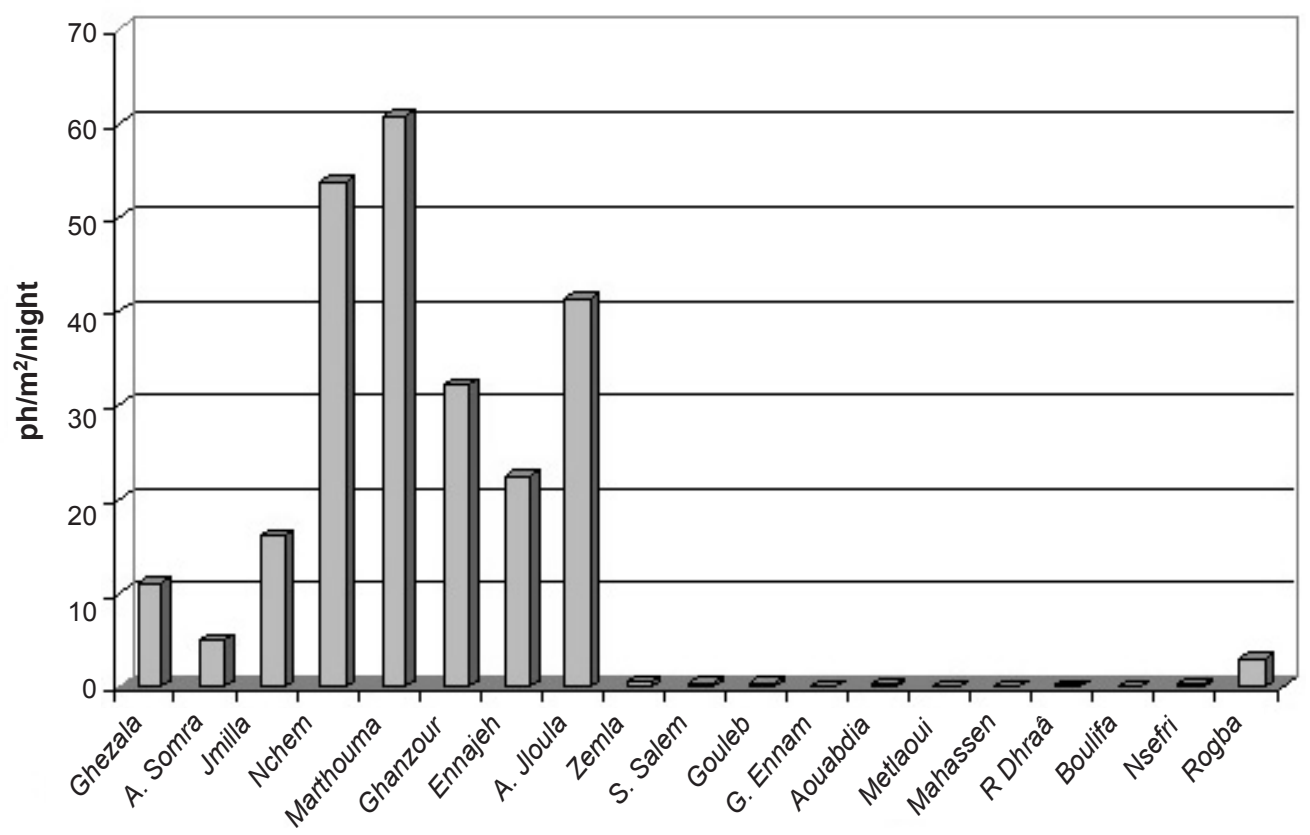

Fig. 3. - Density of phlebotomine sandflies per focus calculated on collections of sticky traps.

Specific richness (S) was higher in CDC captures than in sticky ones (Tables IIa and IIb). Sampled with CDC traps, most of the sites (14 out of 19) have got a specific richness equal or superior to five, with a maxima in central foci situated on the southern side of the Atlas Mountains $(S=10)$. However, Simpson index $\left(I_{S}\right)$ showed a low diversity in all sites. This result is confirmed by the equitability index (E) showing values near to zero. Thus using this kind of traps, we could group the sites as follows: those with an Equitability $\mathrm{E} \leq 0.2$ in which only one species dominates; those with $0.2<$ $\mathrm{E} \leq 0.4$ in which two species co-dominate and finally sites with $0.4<\mathrm{E} \leq 0.6$ in which three species co-dominate (Table IIa). Using sticky traps, Simpson index and equitability showed a higher diversity in some sites so a fourth group where all the species have an equal dominance $(0.6<\mathrm{E}<1)$ was added (Table IIb).

Two foci of the south-east (Nsefri and Rogba) presented specimens of $P$. perniciosus with curved distal portion of aedeagi which can be confused with $P$. longicuspis (Fig. 4). However, the number of coxite hairs varied from 10 to $17($ mean $=14)$ whereas this number varied in $P$. longicuspis sensu stricto from 21 to 27 $($ mean $=24.8)$. In this area only one specimen of $P$. perniciosus displayed the typical bifid aedeagus as the males collected in all other prospected sites.

\section{Phlebotominae of VL SITES}

Among the 955 phlebotomine sandflies identified from captures carried out between July and September in each of the six VL foci, $706(73.9 \%)$ belonged to the genus Phlebotomus including 561 (79.5 \%) Larroussius (Table III). $144(25.7 \%)$ were females shared as follows: 109 (75.7\%) in animal sheds, 29 (20\%) indoors

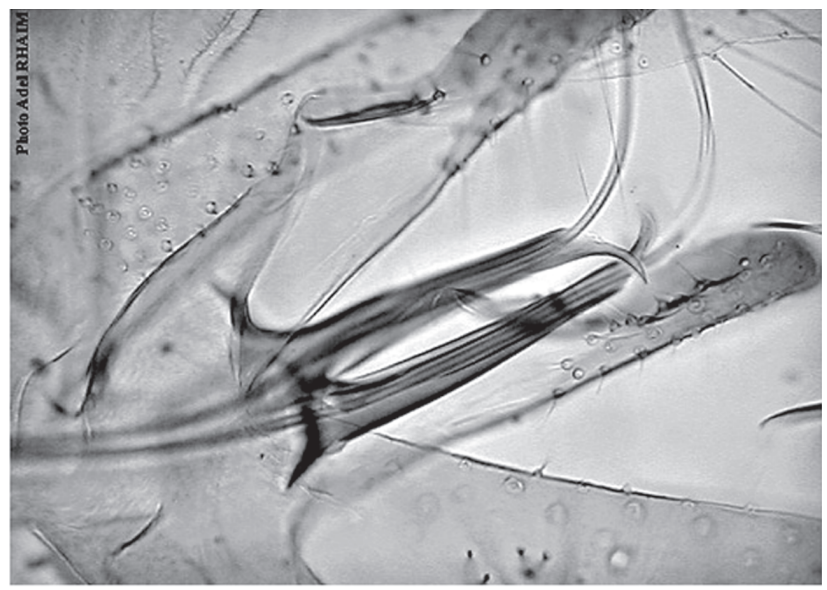

Fig. 4. - Aedeagi of P. perniciosus collected in south-eastern foci.

and six (4.3\%) outdoors. No statistical significance was found according to the site of capture.

The subgenus Larroussius was absent in Garet Ennam, a site located on the border of the area of L. infantum. In Ghezala, Ain Jloula and Sidi Salem the specific composition showed a dominance of $P$. perniciosus. In Marthouma, $P$. perfiliewi was the dominant species in sticky traps whereas $P$. perniciosus was dominant in CDC traps. In the south-western focus of Mahassen P. longicuspis predominated (Tables IIa, IIb and III).

\section{Phlebotominae OF CL Sites}

Among the 7,827 phlebotomine sandflies collected in CL sites, 4,025 (51.5\%) were caught in the northern CLI sites, $505(6.4 \%)$ in the central and south-eastern CLM sites, $421(5.4 \%)$ in the classic south-eastern sites of CLK and finally $2,876(36.7 \%)$ in the emergent sites of CLK. 


\begin{tabular}{|c|c|c|c|c|}
\hline Foci & $\mathbf{S}^{*}$ & $\mathbf{I s}^{* *}$ & $\mathbf{E}^{* * *}$ & Dominant species (relative abundance) \\
\hline Jmila & 6 & 1.29 & 0.06 & P. perfiliewi $(87.4 \%)$ \\
\hline Ghezala & 5 & 2.07 & 0.27 & S. m. parroti (64.8\%); P. perniciosus (23.9\%) \\
\hline A. Somra & 4 & 2.88 & 0.63 & P. perniciosus (50 \%); P. papatasi (21.4 \%); S. m. parroti (21.4 \%) \\
\hline Nchem & 7 & 1.3 & 0.05 & P. perniciosus $(87.6 \%)$ \\
\hline Marthouma & 8 & 1.7 & 0.1 & P. perniciosus $(75.6 \%)$ \\
\hline Ghanzour & 10 & 4.39 & 0.38 & P. perniciosus (32.7 \%); P. papatasi (24.8\%) \\
\hline Ennajeh & 10 & 2.23 & 0.14 & P. perniciosus (64.5\%); P. papatasi $(13.7 \%)$ \\
\hline A. Jloula & 5 & 3.05 & 0.51 & P. perniciosus $(39.2 \%) ;$ P. papatasi $(36.4 \%) ;$ S. fallax $(20.3 \%)$ \\
\hline G. Ennam & - & - & - & - \\
\hline Zemla & - & - & - & - \\
\hline S. Salem & 7 & 3.19 & 0.37 & P. perniciosus (38.7 \%); P. papatasi (38.7\%) \\
\hline Gouleb & 6 & 2.22 & 0.24 & S. fallax $(62.2 \%) ;$ S. m. parroti $(23,6 \%)$ \\
\hline Metlaoui & 5 & 2.86 & 0.47 & P. papatasi (52.9\%); P. alexandri (17.6\%); S. m. parroti (17.6\%) \\
\hline Aouabdia & 3 & 1.41 & 0.21 & P.papatasi $(83.3 \%)$ \\
\hline Nsefri & 8 & 4.34 & 0.48 & P. sergenti (30.2 \%); P. perniciosus (29.1\%); P. papatasi (20.1\%) \\
\hline Rogba & 9 & 3.36 & 0.3 & P. papatasi $(47.1 \%) ;$ P. sergenti $(18 \%)$ \\
\hline Mahassen & 5 & 2.22 & 0.31 & P. papatasi (62 \%); P. longicuspis (24\%) \\
\hline R Dhraâ & 5 & 3.27 & 0.57 & S. m. parroti (41.7 \%); P. papatasi (29.2 \%); S. antennata (20.8\%) \\
\hline Boulifa & 4 & 3.05 & 0.68 & S. m. parroti (43.8\%); P. longicuspis (31.3\%); P. papatasi $(18.8 \%)$ \\
\hline
\end{tabular}

* S: specific richness; ${ }^{* *} \mathrm{I}_{\mathrm{S}}$ : index of Simpson; and *** E: equitability.

Table IIa. - Diversity and dominant species of phlebotomine caught on CDC traps in leishmaniosis sites.

\begin{tabular}{|c|c|c|c|c|}
\hline Foci & $\mathbf{S}^{*}$ & $\mathbf{I s}^{* *}$ & $\mathbf{E}^{* * *}$ & Dominant species (relative abundance) \\
\hline Jmila & 4 & 2.49 & 0.5 & P. perfiliewi (54.3 \%); P. perniciosus (29.6 \%); S. m. parroti (13.6\%) \\
\hline Ghezala & 5 & 2.38 & 0.35 & S. m. parroti $(58.2 \%) ;$ P. papatasi $(23 \%) ;$ P. perniciosus $(17 \%)$ \\
\hline A. Somra & 5 & 2.01 & 0.25 & S. m. parroti (63.3\%); P. perniciosus $(30.3 \%)$ \\
\hline Nchem & 4 & 1.13 & 0.04 & P. perniciosus (94\%) \\
\hline Marthouma & 6 & 1.95 & 0.19 & P. perfiliewi $(65 \%)$ \\
\hline Ghanzour & 9 & 3.64 & 0.33 & P. perniciosus (37.3 \%); S. fallax (29.6\%); P. papatasi $(20.7 \%)$ \\
\hline Ennajeh & 5 & 1.17 & 0.04 & P. perniciosus $(92.2 \%)$ \\
\hline A. Jloula & 4 & 1.59 & 0.2 & P. perniciosus $(77.4 \%)$ \\
\hline G. Ennam & 1 & 1 & - & S. m. parroti $(100 \%)$ \\
\hline Zemla & 7 & 3.37 & 0.4 & P. papatasi (42.7 \%); P. perniciosus (29.8 \%); S. m. parroti (12.9\%) \\
\hline S. Salem & 5 & 2.55 & 0.39 & P. perniciosus $(50.8 \%) ;$ P. papatasi $(35.4 \%)$; S. m. parroti $(19.2 \%)$ \\
\hline Gouleb & 4 & 1.76 & 0.25 & S. fallax $(72.2 \%) ;$ S. m. parroti $(21.1 \%)$ \\
\hline Metlaoui & 5 & 2.47 & 0.37 & P. papatasi $(60 \%) ;$ P. sergenti (13.3\%); S. m. parroti $(13.3 \%)$ \\
\hline Aouabdia & 5 & 2.18 & 0.3 & P. papatasi $(64.7 \%)$; S. m. parroti $(14.7 \%)$; S. antennata $(11.8 \%)$ \\
\hline Nsefri & 6 & 3.31 & 0.46 & P. papatasi $(46.7 \%) ;$ S. fallax $(23.3 \%) ;$ P. perniciosus $(13.3 \%)$ \\
\hline Rogba & 2 & 1.8 & 0.80 & P. papatasi $(66.7 \%) ;$ S. fallax $(33.3 \%)$ \\
\hline Mahassen & 4 & 3.79 & 0.93 & P. longicuspis (33.3 \%); P. papatasi (25\%); S. fallax (25\%); S. m. parroti (16.7\%) \\
\hline R Dhraâ & 3 & 2.47 & 0.74 & P. papatasi $(54.5 \%) ;$ S. antennata $(27.3 \%)$; S. $m$. parroti $(18.2 \%)$ \\
\hline Boulifa & 4 & 2.91 & 0.64 & P. longicuspis $(50 \%)$; P. papatasi $(25 \%)$; S. antennata (12.5\%); P. perniciosus $(12.5 \%)$ \\
\hline
\end{tabular}

* S: specific richness; ** $\mathrm{I}_{\mathrm{S}}$ : index of Simpson; and ${ }^{* * *} \mathrm{E}$ : equitability.

Table IIb. - Diversity and dominant species of phlebotomine caught on sticky traps in leishmaniosis sites.

\begin{tabular}{|c|c|c|c|c|c|c|c|c|}
\hline \multirow[b]{2}{*}{$\begin{array}{c}\text { Form } \\
\text { of leishmaniasis }\end{array}$} & \multirow[b]{2}{*}{ Foci } & \multirow[b]{2}{*}{$\begin{array}{c}\text { Date } \\
\text { of catch }\end{array}$} & \multirow[b]{2}{*}{$\begin{array}{c}\text { Total } \\
\text { sandflies }\end{array}$} & \multirow[b]{2}{*}{$\begin{array}{c}\text { Total } \\
\text { Larroussius }\end{array}$} & \multicolumn{4}{|c|}{ Number (\% among Larroussius) } \\
\hline & & & & & $\begin{array}{c}P . \\
\text { perfiliewi }\end{array}$ & $\begin{array}{c}P . \\
\text { perniciosus }\end{array}$ & $\begin{array}{c}P . \\
\text { longiscuspis }\end{array}$ & $\begin{array}{c}P . \\
\text { langeroni }\end{array}$ \\
\hline \multirow[t]{6}{*}{ VL } & Ghezala & $22 / 09 / 2004$ & 324 & 74 & $6(8,1)$ & $66(89,2)$ & $2(2,7)$ & - \\
\hline & Aïn Jloula & $18 / 07 / 2002$ & 196 & 97 & - & $97(100)$ & - & - \\
\hline & Sidi Salem & $21 / 09 / 2004$ & 49 & 33 & - & $29(78,9)$ & $4(12,1)$ & - \\
\hline & Marthouma & $11 / 09 / 2002$ & 370 & 352 & $169(48)$ & $169(48)$ & $14(4)$ & - \\
\hline & Gt Ennam & $21 / 08 / 2004$ & 5 & 0 & - & - & - & - \\
\hline & Mahassen & $30 / 072003$ & 11 & 5 & - & $1(20)$ & $4(80)$ & - \\
\hline \multirow[t]{3}{*}{ SCL } & Jmila & $07 / 09 / 2002$ & 2,354 & 2,303 & $2,030(88,1)$ & $267(11,6)$ & $6(0,3)$ & - \\
\hline & Aïn Somra & $22 / 09 / 2004$ & 113 & 41 & $1(2,4)$ & $37(90,3)$ & $3(7,3)$ & - \\
\hline & Nchem & $28 / 08 / 2002$ & 1,558 & 1,541 & $39(2,5)$ & $1,382(89,7)$ & $74(4,8)$ & $46(3)$ \\
\hline
\end{tabular}

Table III. - Specific composition of subgenus Larroussius caught by CDC and sticky traps in the studied L. infantum foci. 
Among the 4,025 phlebotomine sandflies identified from captures carried out on August and September in the three CLI sites, 3,902 (96.9\%) belonged to the genus Phlebotomus, of which 3,885 (99.6\%) belonged to the subgenus Larroussius (Table III). 2,039 females of this subgenus were collected mainly in animal sheds $(87 \%$, $\mathrm{p}<0.001)$. In the focus of Jmila situated in the humid stage, $P$. perfiliew $i$ was the dominant species with a relative abundance $\left(\mathrm{A}_{\mathrm{r}}\right)$ varying from $54,3 \%$ (Sticky traps) to $87,4 \%$ (CDC traps) whereas in Aïn Somra (sub-humid) and Nchem, the southern limit of CLI area in semiarid zone, $P$. perniciosus predominated (Tables IIa, IIb and III).

Among the 505 sandflies caught monthly between May and October in the central and southern sites of L. major, 404 (80 \%) belonged to the genus Phlebotomus of which $223(55.2 \%)$ were $P$. papatasi (Tables Ia and Ib). It was a dominant species in all sites, associated with Larroussius species in Zemla, Sidi Salem, Mahassen and Boulifa and with Sergentomyia species specially in fauna sampled with sticky traps (Table IIa and IIb). 69 females of $P$. papatasi were caught. A significantly higher proportion of these females $(56.5 \%)$ was collected in animal sheds $(\mathrm{p}<0.01)$. However a non negligible proportion (24.6\%) was caught indoors.

Among the 3,297 phlebotomine sandflies regularly caught between April and October in CLK sites, 2,318 (70.3\%) belonged to the genus Phlebotomus (Tables Ia and $\mathrm{Ib})$.

In Nsefri, the best known south-east focus of CLK; $P$. perniciosus and $P$. sergenti were the co-dominant species with $P$. papatasi (Table IIa). In Rogba, the second best known focus, $P$. papatasi and $P$. sergent $i$ were the dominant species (Table IIa). 37 females of $P$. sergent $i$ were caught in these two foci and $65 \%$ of them were indoors. 36 females of $P$. perniciosus were collected, of which $55 \%$ were in animal sheds. However no statistical significance was found according to the site of capture for both species.

In Ghanzour and Ennajeh, the emergent foci of the Centre, $P$. perniciosus was a dominant species with a significantly higher proportion of females caught in animal sheds $(\mathrm{p}<0.01)$. P. alexandri represented the highest relative abundance among subgenus Paraphlebotomus ( $85.9 \%$ ) with $55 \%$ of female specimens present indoors (Tables Ia and Ib). In Gouleb, Sergentomyia was the dominant genus (Tables IIa and IIb). P. perniciosus was rare $(0.8 \%)$ and the subgenus Paraphlebotomus was represented exclusively by P. alexan$d r i$ (Tables Ia and Ib).

In the mixed focus of Metlaoui (south-west), only some specimens were collected, although the captures had been repeated twice a month. They were three $P$. alexandri, two $P$. sergenti, one $P$. perniciosus, $18 P$. papatasi and eight specimens of subgenus Sergentomyia (Tables Ia and $\mathrm{Ib}$ ).

\section{DISCUSSION}

r 1 n order to identify the phlebotomine sandfly populations in Tunisian leishmaniosis sites, an entomological survey was carried out through three entomological seasons (2002-2003-2004) in 19 visceral and cutaneous leishmaniosis areas, located in six bioclimatic zones. Two complementary kind of traps were used: CDC light traps acting by attraction and sticky ones sampling by interception.

In the studied Tunisian leishmaniosis sites, we found 12 species of Phlebotominae out of the 16 recorded in Tunisia (Croset et al., 1978; Depaquit et al., 1998). P. (L.) ariasi, P. (L.) chadlii, P. (Pa.) riouxi and S. (S.) christophersi were not found. Our failure to find them is probably due to their rarity and their presence in natural biotopes that were not sampled in our study (Croset et al., 1978). Eight out of the 12 collected species belonged to the genus Phlebotomus, proven vectors of human leishmaniosis in the Old World (KillickKendrick, 1985; Killick-Kendrick, 1990). Among these species, four belong to the subgenus Larroussius, the proven vector of $L$. infantum in the Mediterranean basin, and three were Paraphlebotomus, among which is found $P$. sergenti the proven vector of $L$. tropica in the Old Word and the last was $P$. papatasi the proven vector of L. major (Killick-Kendrick, 1990).

The dominance of Larroussius species in northern sites, $P$. papatasi in the south-western ones and their co-dominance in the centre is in accordance with the distribution of L. infantum and L. major in Tunisia (Tables IIa and IIb, Figs 1 and 2). The low density found in the historical CLM focus of Metlaoui in the south-west may indicate the high competence of the local populations. It can also suggest that CL could be transmitted out of the village. Sites located on the southern side of the Atlas Mountains are transitional ones. They have been submitted to northern Mediterranean and southern Ethiopian influences and therefore exhibit a mixture of mediterranean species as $P$. perniciosus and $P$. perfiliewi and peritethysian ones as $P$. papatasi, $P$. sergenti and $P$. alexandri (Croset et al., 1978). In spite of the high proportion of $P$. perniciosus in south-eastern sites, no human leishmaniosis cases due to L. infantum were reported. It's important to underline that the east-southern population of $P$. perniciosus is morphologically different from populations caught in L. infantum foci. The male specimens does not present the typical bifid aedeagi but exhibit curved ones. It can be confused with $P$. longicuspis, but has been differenciated by the number of coxite hairs which is higher in P. longicuspis sensu stricto as described on specimens from Morocco and Spain. (Benabdennbi et al., 1999; Martin-Sanchez et al., 2000; Pesson et al., 2004; Guernaoui et al., 2005). 
In five out six prospected VL sites, the subgenus Larroussius predominated. It was absent in Garet Ennam, a site located near the south-western limit of the area of VL (Fig. 1), where the absence of recent human cases can be explained by a rigorous climate limiting the occurrence and the abundance of the vector. In the other VL sites, the succession from north to south, of different Larroussius species explains the large geographical distribution of VL in Tunisia. In fact, L. infantum is not restricted to a particular Larroussius species and can be encountered in different bioclimates (KillickKendrick, 1985; Rioux, 2001). P. (L.) perniciosus has got the largest distribution $(\mathrm{D}=84 \%$ ) (Tables Ia and Ib). It was the most abundant Larroussius species in most studied VL sites (Ghezala, Aïn Jloula and Sidi Salem) and probably represents the main vector of $\mathrm{VL}$ in northern and central Tunisia as reported in other Mediterranean countries (Table IIa and IIb) (AlvesPires, 1984; Bettini et al., 1986; Rioux et al., 1986b; Maroli et al., 1988; Izri et al., 1990; Izri et al., 1992). However, in Marthouma, the dominance of $P$. perniciosus in CDC traps and $P$. perfiliewi in sticky traps suggests that more than one species could be incriminated in the transmission (Table IIa and IIb) (Dancesco et al, 1970; Alves-Pires, 1984; Rioux et al., 1986b; Izri et al., 1992). In Mahassen, the southern focus situated in a oasis in the saharan bioclimatic zone, $P$. perniciosus was very rare. $P$. longicuspis, the dominant Larroussius species, could be the main vector in this area as reported in other Saharan foci (Tables IIa and IIb) (Rioux, 2001).

In CLI sites, specimens of subgenus Larroussius represented almost the totality of sandflies caught (95\%). In Jmila, a focus located in the humid bioclimatic zone, $P$. perfiliewi the proven vector of CLI in Algeria and Italy, was the dominant species (Tables IIa and IIb) (Izri \& Belazzoug, 1993; Maroli et al., 1988). However, in Ain Somra and Nchem located in the subhumid and the semi-arid bioclimatic stages $P$. perfiliewi was rare. P. perniciosus was the dominant specie, and probably can be the vector of CLI in these areas.

Larroussius females predominated in animal sheds as demonstrated in previous studies (Dansesco et al., 1969). A non negligible proportion of females was caught indoors in VL sites and outdoors in CLI sites. Therefore, a transmission of these two forms of leishmaniosis could occur in different sites.

In the arid CLM sites of the centre and the south-west, $P$. papatasi the proven vector of $L$. major in Tunisia was a dominant species with a significantly higher proportion of females in animal sheds and a non negligible proportion indoors (Tables IIa and IIb) (Ben Ismail et al., 1987). In fact, although this species is known to be endophilic, it was also already collected with a high abundance outdoor (Rioux et al., 1986a; Maroli et al.,
1994). In particular sites located on the side of stony hills, as Gouleb, species of Paraphlebotomus were abundantly collected as reported in similar biotopes of Saudi Arabia (Büttiker \& Lewis, 1983). The presence of this subgenus could explain the co-existence, with L. major, of L. killicki a closely related complex to L. tropica (Rioux et al., 1986d).

In Tunisia, the vector of $L$. killicki still unknown. It could belong, as reported for the closely related complexes, L. tropica and L. infantum, to the subgenus Paraphlebotomus or Larroussius (Serre \& Roux, 1986; KillickKendrick, 1990; Lawyer et al., 1991). In the well known foci of the south-east, the dominante species, $P$. (Pa.) sergenti, proven vector of $L$. tropica in the Old World is probably the vector of this form (Rioux et al, 1986c; Killick-Kendrick, 1990). However, interestingly $P$. (L) perniciosus was also abundant in the historic foci of Nsefri (Tables I and IIa) and seems to be endophilic in its behaviour. In the emerging foci of L. killicki of the Centre, $P$. perniciosus was a dominant species in some sites whereas it was very rare in others (Tables IIa and IIb). In these sites, the subgenus Paraspblebotomus was always present. Among this subgenus, only some specimens of $P$. sergenti were found whereas $P$. alexandri was relatively abundant with a non negligible proportion of females indoors which suggests its possible role in the transmission (Tables Ia and Ib).

\section{CONCLUSION}

$\mathrm{T}$ This study is a contribution to the knowledge of phlebotomine sandflies of human leishmaniosis sites in Tunisia and its possible consequences in the epidemiology of leishmaniosis. It would gain in being compleeted by the isolation and identification of the parasite in potential vector species particulary those present in Leishmania killicki foci.

\section{ACKNOWLEDGEMENTS}

T This study was carried out with the financial support of the Research Unit "Parasitoses emergentes" 02/UR/08-05 Faculté de Médecine de Tunis. We thank the Regional Directors and heads of Services of Public Health: Dr A. Garraoui (Bizerte), N. Kouzana (Beja), Dr M. Hamdi (Siliana), Dr H. Hadhri (Kairouan), Dr MZ Ahmadi (Sidi Bouzid), Dr H. Khmaïs and Dr B. Mahmoudi (Kasserine), Dr S. Tlijani (Gafsa), Dr S. Doukali and Dr R. Dani (Tozeur), Dr Kodia and Dr M. Raouene (Tataouine), all of whom facilitated the field work together with Miss Karima Hmida and the health agents who contributed to the achievement of this survey. 


\section{REFERENCES}

Alves-PIres C. Les phlebotomes du Portugal. I - Infestation naturelle de Phlebotomus ariasi Tonnoir, 1921 et Phlebotomus perniciosus Newstead, 1911, par Leishmania dans le foyer zoonotique de Arrabida (Portugal). Annales de Parasitologie Humaine et Comparée, 1984, 59, 521-524.

Anderson C. Chronique du Kala-azar en Tunisie. Archives de l'Institut Pasteur de Tunis, 1934, 455.

Anonymous. Bulletin épidémiologique de la Direction des Soins de Santé de Base, Ministère de la Santé Publique, Tunisie, 2003.

Aoun K., Bouratbine A., Harrat Z., Guizani I., Mokni M., Bel Hadj Ali S., Ben Osman A., Belkaied M., Dellagi K \& Ben Ismail R. Données épidémiologiques et parasitologiques concernant la leishmaniose cutanée sporadique du nord tunisien. Bulletin de la Société de Pathologie Exotique, 2000, 93, 101-103.

Aoun K., Tioulri H., Ghrab J. \& Boufaroua M. Les lacs collinaires et santé humaine : quelle situation en Tunisie? Microbiologie et Hygiène Alimentaire, 2004, 16, 37-40.

Baldi L., Mizzoni V \& Guarino A. Canine leishmaniasis in Campania: new and old foci. Parassitologia, 2004, 46, $217-$ 220.

Bel Hadj S., Pratlong F., Hammami M., Kallel K., Dedet J.P. \& CHAKer E. Human cutaneous leishmaniasis due to Leishmania infantum in the Sidi Bourouis focus (Northern Tunisia): Epidemiological study and isoenzymatic charachterisation of the parasites. Acta tropica, 2003, 85, 83-86.

Benabdennil I., Pesson B., Cadi-soussi M. \& Morillas MarQUEZ F. Morphologicaland isoenzymatic differentiation of sympatric populations of $P$. perniciosus and $P$. longicuspis (Diptera: Psychodidae) in northern Morocco. Journal of Medical Entomology, 1999, 36, 116-120.

Ben Ismail R., Helal H, Bach-Hamba D. \& Ben Rachid M.S. Infestation naturelle de Phlebotomus papatasi dans un foyer de leishmaniose cutanée zoonotique en Tunisie. Bulletin de la Société de Pathologie Exotique, 1987, 80, 613-614.

Ben Ismail R. \& Ben RACHId M.S. Épidémiologie des leishmanioses en Tunisie, in: Maladies tropicales transmissibles. AUPELF-UREF, Paris, 1989, 73-80.

Ben Rachid M S. \& Ben Ismail R. Parasitoses et environnement en Tunisie. Symposium international sur les sciences de l'environnement. INRST Éditions, Tunis, 1989, pp. 1728.

Bettini S., Gramiccia M., Gradoni L. \& Atzeni M.C. Leihmaniasis in Sardinia: II. Natural infection of Phlebotomus perniciosus Newstead, 1911, by Leishmania infantum Nicolle, 1908, in the province of Cagliari. Transaction of Royal Society of Tropical Medecine and Hygiene, 1986, 80, 458459.

Bouratbine A., Aoun K., Chahed M.K. \& Ben Ismail R. Données épidémiologiques sur la leishmaniose viscérale infantile en Tunisie en 1993. Médecine et Maladies Infectieuses, 1998, 28, 446-447.

Bouratbine A., Aoun K., Ghrab J., Harrat Z., Ezzedini M.S. \& ETLIJANi S. Spread of Leishmania killicki to central and south-west Tunisia. Parasite, 2005, 12, 59-63.
BÜTTIKER W. \& LeWIS D.J. Insects of Saudi Arabia. Some ecological aspects of Saudi Arabian phlebotomine sandflies (Diptera: Psychodidae), in: Fauna of Saudi Arabia. Wittmer W. \& Buttiker W. (eds), 1983, 5, 479-530.

Croset H., Rioux J.A., Maistre M. \& Bayar N. Les phlébotomes de Tunisie (Diptera, Phlebotomidae). Mise au point systématique, chorologique et éthologique. Annales de Parasitologie Humaine et Comparée, 1978, 53, 711-749.

DANCESCO P., Romain \& Chadli A. Observation sur les écotypes rencontrés à Tunis. Archives de l'Institut Pasteur de Tunis, 1969, 46, 378-396.

Dancesco P., DEDET J.P., BEN OSMAN F. \& Chadli A. Les phlébotomes capturés dans des foyers de leishmaniose canine à Tunis. Rôle probable de $P$. perniciosus et $P$. perfiliewi dans la transmission. Archives de l'Institut Pasteur de Tunis, 1970, 47, 65-88.

Depaquit J., Léger N \& Killick-Kendrick R. Description de Phlebotomus (Paraphlebotomus) riouxi n. sp. (Diptera : Psychodidae) d'Afrique de Nord. Parasite, 1998, 5, 151158.

DSSB. Rapport annuel des activités. Direction des soins de santé de base, Ministère de la santé, Tunisie, 2001.

Gebre-Michael T., M. Balkew, Ali A., Ludovisi A. \& GramicCIA M. The isolation of Leishmania tropica and L. aethiopica from Phlebotomus (Paraphlebotomus) species (Diptera: Psychodidae) in the Awash Valley, notheastern Ethiopia. Transactions of the Royal Society of Tropical Medecine and Hygiene, 2004, 98, 64-70.

Ghrab J, Rhim A, Bach-Hamba D, Aoun K. \& Bouratbine A. Phlebotomus (Larroussius) langeroni Nitzulescu, 1930 en Tunisie : présence de la femelle et actualisation de la distribution géographique. Bulletin de la Société de Pathologie Exotique, 2005, 98, 411-412.

Gounot M. \& Le Houerou H.N. 1967 Essai de synthèse sur la végétation et la phyto-écologie tunisiennes, in : Élément de botanique et de phyto-écologie tunisiennes, Tome I, Nabli M.A (éd.). Faculté des Sciences de Tunis et MAB, 1989, 387 p.

Guernaoui S., Pesson B., Boumezzough A. \& Pichon G. Distribution of phlebotomine sandflies, of the subgenus Larroussius, in Morocco. Medical and veterinary Entomology, 2005, 19, 111-115.

Izri M.A., Belazzoug S., Boudjebla Y., Dereure J., Pratlong S., Delalbre-Belmonte Presiozo J., HaAs P. \& Le Fichoux Y. Leishmania infantum MON-1 isolé de Phlebotomus perniciosus, en Kabylie (Algérie). Annales de Parasitologie Humaine et comparée, 1990, 3, 151-152.

Izri M.A., Marty P., Rahal A., Lelievre A. Ozon C., Baldelli G. \& Rioux J.A. Phlebotomus perniciosus Newstead, 1911 naturellement infesté par des promastigotes dans la région de Nice (France). Bulletin de la Société Pathologique Exotique, 1992, 85, 385-387.

Izri M.A. \& Belazzoug S. Phlebotomus (Larroussius) perfiliewi naturally infected with dermotropic Leishmania infantum at Tenes, Algeria. Transaction of Tropical Medecine and Hygiene, 1993, 87, 399.

Jacobson R.L. Leishmania tropica (Kinetoplastida: Trypanosomatidae) a perplexing parasite. Folia parasitologica, 2003, 50, 241-250. 
KilLick-Kendrick R. Some epidemiological consequences of the evolutionary fit between Leishmaniae and their phlebotomine vectors. Bulletin de la Société Pathologique Exotique, 1985, 78, 747-755.

KILLICK-KENDRICK R. Phlebotomine vectors of the leishmaniasis: a review. Medical and Veterinary Entomolology, 1990, 4, $1-24$.

Lawyer P.G, Mebrahtu Y.B., Ngumbi P.M., Mwanyumba P., Mbugua J., Kinlu G., Kipkoech D., Nzovuj. \& Anjili C.O. Phlebotomus guggisbergi (Diptera: Psychodidae), a vector of Leishmania tropica in Kenya. American Journal of Medicine and Hygiene, 1991, 44, 290-298.

Léger N., Pesson B., Madulo-Leblond G. \& Abonnec E. Sur la différentiation des femelles du sous-genre Larroussius Nitzulescu, 1931 (Diptera-Phlebotomidae) de la région méditerranéenne. Annales de Parasitologie Humaine Comparée, 1983, 58, 611-623.

Maroli M., Bigliochi F. \& Khoury C. Sandflies in Italy: observations on their distribution and methods for control. Parassitologia, 1994, 36, 251-264.

Maroli M., Gramiccia M., Gradoni L., Ready P.D., Smith D.F. \& Aquino C. Natural infection of phlebotomine sandflies with Trypanosomatidae in central and south Italy. Transaction of the Royal Society of Tropical Medicine and Hygiène, 1988, 82, 227-228.

Martin-Sanchez J., Gramiccia M., Pesson B. \& Morillas-MarQUEZ F. Genetic polymorphism in sympatric species of the genus Phlebotomus, with special reference to Phlebotomus perniciosus and Phlebotomus longicuspis (Diptera, Phlebotomidae). Parasite, 2000, 7, 247-254.

Pesson B., Ready J.S., Benabdennbi I., Martin-Sachez J., EsseGHir S., Cadi-Soussi M., Morillas-Marquez F. \& Ready P.D. Sandflies of Phlebotomus perniciosus complex: mitochondrial introgressi and a new sibling species of Phlebotomus longicuspis in Moroccan Rif. Medical and Veterinary Entomology, 2004, 18, 25-37.

Rioux J.A., Pereires J., Killick-Kendrick R., Lanotte G. \& Bailly M. Écologie des leishmanioses dans le sud de la France. 17. - Échantillonnage des phlébotomes par le procès des pièges adhésifs. Comparaison avec la technique de capture sur appât humain. Annales de Parasitologie Humaine Comparée, 1982, 57, 631-635.

Rioux J.A., Gullevard E., Dereure J., Lanotte G., Denial M., Pratlong F., Serres E. \& Belmonte A. Infestation naturelle de Phlebotomus papatasi (Scopoli, 1786) par Leishmania major MON-25, in : Leishmania. Taxonomie et phylogenèse. Applications éco-épidémiologiques, Rioux J.A. (éd.). IMEEE, Montpellier, 1986a, 471-480.

Rioux J.A., Guilevard E., Gallego M., Moreno G., Pratlong F., Portus M., Rispail P., Gallego M. \& Bastien P. Phlebotomus ariasi Tonnoir, 1921 et Phlebotomus perniciosus Newstead, 1911 vecteur du complexe Leishmania infantum dans un même foyer, in : Leishmania. Taxonomie et phylogenèse. Applications éco-épidémiologiques. Rioux J.A. (éd.). IMEEE, Montpelier, 1986b, 439-444.

Rioux J.A., Lanotte G., Petter F., Dereure J., Akalay O., Pratlong F., Velez I.D., Fikri N.B., Maazoun R., Denial M., Jarry D.M., Zahaf A., AshFord R.W., CAdi-Soussi M., KIllick-KenDrick R., Benmansour N., Moreno G., Perieres J., Guilvard E.,
Zribi M., Kennou M.F., Rispail P., Knechtli R. \& Serres E. Les leishmanioses cutanées du bassin Méditerranéen occidental. De l'identification enzymatique à l'analyse éco-épidémiologique. L'exemple de trois "foyers" tunisien, marocain et français, in : Leishmania. Taxonomie et phylogenèse. Applications éco-épidémiologiques, Rioux J.A. (éd.). IMEEE, Montpellier, 1986c, 365-395.

Rioux J.A., Lanotte G. \& Pratlong F. Leishmania killicki n. sp. (Kinetoplastida : Trypanosomatidae), in : Leishmania Taxonomie et phylogenèse. Applications éco-épidémiologique, Rioux J.A. (éd.). IMEEE, Montpellier, 1986d, 139142.

Rioux Ja., Lanotte G., Serres E., Pratlong F., Bastien P. \& Perieres J. Taxonomy of Leishmania. Use of isoenzymes. Suggestions for a new classification. Annales de Parasitologie Humaine et Comparée, 1990, 65, 111-125.

Rioux J.A. Trente ans de coopération franco-marocaine sur les leishmanioses : dépistage et analyse des foyers. Facteurs de risque. Changements climatiques et dynamique nosogéographique. Association des Anciens Élèves de l'Institut Pasteur, 2001, 168, 90-101.

Rioux J.A. \& De La Roque S. Climat, leishmanioses et trypanosomoses, in : Changements climatiques, maladies infectieuses et allergiques, Rodhain F. (éd.). Sc. Méd., 2003, 4160.

Serres E. \& Roux M. Pratique de la classification automatique, in : Leishmania Taxonomie et phylogenèse. Applications éco-épidémiologique, Rioux J.A. (éd.). IMEEE, Montpellier, 1986, 27-39.

Spellerberg I.F. \& Fedor P.J. A tribute to Claude Shannon (1916-2001) and a plea for more rigorous use of species diversity and the "Shannon-Wiener" Index. Global Ecology and Biogeography, 2003, 12, 177-183.

Reçu le 18 août 2005 Accepté le 5 décembre 2005 